\title{
The Impact of Writing Portfolio Assessment on Developing Editing Ability of Iranian EFL Learners
}

\author{
Mansoor Fahim \\ Allameh Tabatabaee University, Tehran, Iran \\ Shahriar Jalili \\ Isla mic Azad University, Islam Abad, Iran
}

\begin{abstract}
Developing autonomy among students has been one of the major concerns in second language instruction. Nowadays portfolio assessment as an alternative form to traditional evaluation has found its place in writing pedagogy. Present investigation was designed to study a group of thirty eight Iranian EFL learners with the aim of investigating the possible effects of using writing portfolio assessment on developing the ability of editing among Iranian EFL learners. The learners were asked to perform some writing tasks. Then they edited their own papers and corrected their writing products using the five categories of content, organization, grammar, spelling, and mechanics. There was a continuous dialogue between the teacher and the learners. The result indicated that the learners could be trained to use editing in their writing. Editing seems to be an effective way for higher proficiency learners to improve the organization of their writing.
\end{abstract}

Index Terms - assessment, portfolio, portfolio assessment, editing, writing ability

\section{INTRODUCTION}

In the second or foreign language learning process, assessment plays a very important role. According to Moya and O'Malley (1994) where standardized or traditional tests such as quizzes and term papers are used to serve a purpose in education, they are neither infallible nor sufficient. They believe that any single score, whether it is a course grade or a percentile score from a norm-refe renced test almost always fails to accurately report student overall progress. Therefore, in recent years language teachers have started using non-test assessment options such as portfolios which adhere to the criteria for adequate assessment.

Considering the importance of writing, Hamp -lyons (1994) concluded that in portfolio as sessment the focus is on the learners and what they are doing in the classroom. Portfolios are potent devices in teaching and learning writing. In addition, a portfolio approach provides students with opportunities to revise, edit, and ask for help, and they can evaluate what they have learned about learning. The reflection due to the editing process helps the learners promote their learning. When managing their writing portfolio, the students become active in and responsible for their learn ing and develop a sense of ownership. Therefore, because of the incompatibility of process learning and product assessment and disagreement between the information needed and the information derived from standardized testing alternative forms of assessment such as portfolios are required. They need to go through an editing process that gives them enough time to go over their works with critical eyes. This study was based on the assumption that portfolio as sessment may lead to the development of the strategy of editing among EFL learners. An attempt was made to see if there was any change in using the ability of editing due to use of writing portfolio as sessment. There fore, it was assumed that through the strategy of editing the learners can take control of the feedback they receive, and teachers are enable to provide effective feedback. The learners need to develop criteria, so that they learn to reflect and edit their own works.

\section{REVIEW OF LITERATURE}

According to structuralis m model, teachers drilled various grammar forms expecting students to develop the skill needed to communicate via written message; this approach has created in students an unproductive and inappropriate orientation toward composition (Brown, 2001). Later on, there was a change in the approach to writing. Zamel (1982) has claimed that successful writers go through a process of revising and redrafting their thoughts, and as they write they come to a final expression of theirs ideas. This is what that happens in portfolio assessment as one of the alternative approaches to product oriented assessment. Some educators (e.g. Ferris, 1995) have claimed that in this approach instruction and assessment are involved from the beginning in every stage of the writing process and not the end product.

In portfolio writing, students become aware of and use the strategy of editing when revising their work. Zamel (1982) suggested that this includes not just editing for mechanical errors such as grammar and vocabulary, but also looking a 
larger element of text organization and meaning; the process that the learners go through from prewriting to drafting, revising and final writing.

Portfolios have been embraced in a variety of contexts and have become very common in language classes and college composition programs (Yancey 1992; Belanoff and Dickson 1991). A qualitative research carried out by Marefat (2004) in Allameh Tabatabai University indicated a number of recurring themes, patterns of student's reactions. In all, it was suggestive of a general positive toward portfolio use. When students reviewed their works, they were mainly obsessed with grammar and spelling i.e. surface level correction.

Results of a study by Grace-Ann Dolan in the 96-97 school year among sponsored students in Concordia suggested that portfolio could have a positive effect on the process of being a sponsored student and on the sponsored students. Portfolio made students and teachers accountable to support process. Also, portfolios helped students to become actively involved in assessing their needs, progress, achievement, and effort. Portfolio would be an instructional tool to help sponsored students to become independent learners who could judge their own learning.

\section{DEFINITION}

Sutton, R (1995) defined a portfolio as a case for keeping files designed to illustrate or exemplify something or someone. Portfolio is developed to contain actual samples or representations of works produced by our pupils.

\section{HOW PORTFOLIOS ARE JUST IFIED?}

Whereas standardized tests are used as an anchor for school - based assessment (Wiggins 1989, cited in Moya \& O'Malley 1994), they are not sufficient tools, because a single score does not tell us accurately about subjects' overall progress. Therefore, in ESL education portfolio is used as an innovative procedure that combines both formal and informal techniques for monitoring student language development; it includes multiple measures and interprets them as an integrated unit.

Moreover, the portfolio procedure can be easily adapted to classroom needs, because portfolio assessment is a classroom - based language procedure, data on students progress are available continually and can be used formatively. Also, because portfolio as sessment in not limited to quantifiable, multiple - choice techniques, attention can be directed to assessing a variety of higher level skills such as the ability to handle different processes in writing. A frequent complaint about traditional measures of writing ability is that they undermine regular classroom instruction. These days writing teachers like to teach using a process approach in which students spend time selecting the subjects they will write about, deciding on a viewpoint, finding materials to include in their essays, drafting, and revising before submitting a finished essay. Portfolios reflect the kinds of instruction valued in composition and therefore judgments made based on portfolios are claimed to be inherently more meaningful.

\section{LIMIT ATIONS OF PORTFOLIOS}

There are substantial concerns about the use of portfolio assessment. Since portfolio takes different shapes in different classes, it may be endangered. It causes lack of consistency, reliability, and equity across classes and schools. Portfolio assessment can be protected by building a common understanding of goals and expectations, and collecting several indicators for each goal however, it can be very time consuming for teachers and educators. Furthermore, learners need to understand the evaluation process if portfolios are to mean to them. Mousavi (2002) referred to validity and reliability as the limitations of portfolio assessment. He doubts the extent a portfolio exemplifies students work and instruction.

\section{METHOD}

\section{PARTICIPANTS}

In order to carry out the study, thirty eighty males of 20 to 24 years of age were selected. They were Persian natives and mostly from middle class families. They were studying at the advanced level in NOOR Eng lish institute in Tehran. Apart from receiving formal instruction during the course they had little chance of practicing English or visiting English natives outside the classroom. They were randomly divided into two groups of nineteen students, one of which was considered as the experimental group and the other one as the control group. All of the subjects had studied New Interchange series which had no correspondence to what they were learning at school. Most of them had started learning English from childhood; a few of them from adulthood, but all of them, without exception, had studied New Interchange books from Elementary level.

\section{PROCEDURE}

Instruments used in this study involved a Barron's TOEFL test (copyright 2005), a pre-test and a post-test on writing, six writing tasks, a portfolio assessment form, and an interview consisting of nine questions. Both standardized and informal instruments were used to elicit specific kind of information about learners' progress. Techniques of 
standardized proficiency tests (TOEFL) as well as non-test techniques such as teacher ratings, checklists, student selfratings, writing samples, and interviews were considered to get enough information about the learners' progress.

First, to check the homogeneity of the group a TOEFL test was utilized. This test just included grammar and vocabulary points. It consisted of 90 multiple choice items, including 40 questions of written expression and structure and 50 questions of reading comprehension and vocabulary, and the test had a total of 90 points. The participants were asked to answer the questions in 80 minutes. Based on the results of such a test the subjects were classified into three groups: (1) high achievers (2) intermediate achievers (3) low achievers. It should be mentioned that the researcher assigned 70 to high achievers, 60-70 to intermediate achievers, and below 60 to low achieves.

Second, since the portfolio writing itself was considered the treatment, to investigate its effects a writing pre -test and a post-test was conducted. The participants were asked to write on the subject agreed on by all of them at the beginning of the course. This written work was considered as the pretest on writing. Then at the end of the course the best work of participants was taken as the post test on writing. Because there was no explicit treatment in this study, the writing portfolios that the participants performed during the course were considered as one of the instruments. The topics for the writings were mutually selected by both the teacher and students.

Third, the portfolio assessment was conducted for experimental group. This phase included planning the assessment purposes and evaluating them according to the objectives, establishing the measurement criteria, introducing portfolio assessment to the learners, supervising the portfolio as sessment process, and finally evaluating the portfolios.

Fourth, during the course subjects were required to write to their teacher. It included a copy of their completed work and the comments they had made. The class was held every week for a complete semester and the participants were required to write essay at home. Because the portfolio as sessment process in this study focused on students' reflections on their works, it served as a reflective tool. Therefore, the researcher wanted his subjects to learn from reflecting on the experience of accomplishing a portfolio project. While the learners were doing their assignment, every item to be kept, in whatever form, was provided with comments and the reason for selection. The learners annotated the items they had chosen, and the teacher provided them with effective feedback in best statements on the annotation sheet. The learners corrected their own papers, and expressed their views on the items that they were uncertain about before delivering them to the teacher. The main responsibility of choosing items stood with the learners, and the teacher added to them one more, if necessary, to complement the learners' choices. The most important part of the portfolio assessment process was the students' reflection on their works, choice of significant items, and the specific reasoning that resulted in editing and correcting their papers not the quantity of items. Therefore it happened that a portfolio did not contain a balance of different areas of items i.e. different learners edited some items more than others. The process took the form of a dialog between the teacher and the learners, i.e., the teacher felt the need to respond in a few words to the students' writings. The papers already commented on by the teacher were returned. Next session the subjects made their notes on the processed samples. While evaluating and processing writing the subjects kept all the material including whatever they had used in their portfolios, a reflective section, a writer's autobiography written early in the term, one timed piece written under conditions uniform across the class, evidence of a writing process including peer responses, teacher forms, and multiple drafts demonstrating significant revision and at least one response sheet from a writing teacher. Toward the end of the term, students submitted to their instructors a complete portfolio for formal assessment. Instructors reserved the right to refuse to submit the portfolio to the assessors if the portfolio was incomplete, or if the student has failed to meet other course requirements. During final week students would be given the opportunity to see the outcome of the assessment. Fifth, Portfolios were read and scored by members of the English/writing raters. Each portfolio was read by two different readers. Readers were to work toward consensus. The learners' portfolios were evaluated and graded via a teacher-made evaluation sheet by two raters. The decision was based on holistic perception of the writing according to the five categories (content, organization grammar, spelling , and mechanics), and an analytical evaluation of each of them. The reliability for two raters was 0.94 for the pre-test and 0.91 for the post-test. If consensus could not be reached, a third reader will be used. Finally, subjects were interviewed based on nine questions provided in advance by teachers to record their views on advantages and disadvantages of portfolios.

\section{RESULTS AND DISCUSSION}

As a teacher teaching English in Iranian schools, the researcher was curious about the prospect of using editing in students' writing and improvement of their writing proficiency. More specifically, the focus was on investigating the use of this technique and its effects in terms of improvement in writ ing. There were two independent groups in this study including the experimental group and the control group. A pre-test and post-test design was used to answer the research question. To analyze the data, the difference between two groups was derived from the difference between the results of the post-test and the pre-test of each individual subject. There were two groups (Experimental group and Control group) and three subgroups (high achievers, intermediate achievers, low achievers) representing the indepe ndent variables of the study (portfolio assessment \& sub-groups). The best approach to find out the possible effects of two independent variables on the dependent variables (writing proficiency \& editing) was Analysis of Variance (ANOWA).

To investigate the hypothesis among the three subgroups (high achievers, intermediate ach ievers, low achievers) Chi Square was used and the outcomes were checked with regard to the learners' ability to edit their papers. The findings 
showed that the achieved $\mathrm{X}$ was less than the critical level (0.05) therefore editing was different among the three subgroups.

TABLE1.

THE RESULTOF CHI-SQUARE FOR THREE SUB-GROUPS

\begin{tabular}{|l|l|l|l|}
\hline$X^{2}=73.03$ & $\mathrm{df}=4$ & $\mathrm{P}=0.001$ & $\mathrm{P}<0.05$ \\
\hline
\end{tabular}

In order to come up with the final decision about students' progress with regard to their ability to edit others' papers, randomly one or two pieces of writing of the their peers were given to them to edit. And at last it was decided whether students had gained the ability to edit or not. The results depicted that the experimental group outperformed the control group with regard to their ability to edit their peers' papers. The portfolio enabled the learners to edit the papers of their own peers. However, the high and intermediate achievers performed differently from what the low achievers did. The high and intermediate achievers were more concerned with content and organization, however, the low achievers focused on grammar, spelling, and mechanics while correcting their peers' papers.

According to the subjects, the most important reasons for the effectiveness of this technique was that it facilitated the teacher's understanding of their compositions and enabled the teacher to learn about the problems the learners encountered in writing, so that he could provide the feedback needed. One more reason was that when making comments, the students had to look at their compositions critically and analytically, as a result they were more receptive to the teachers' feedback based on the annotations. However the results of the pos-test showed that only high achievers improved their writing relatively after using this technique.

The students in different sub-groups used this technique with different focuses. This difference can be shown by the different annotations they made. With regard to the percentage of editing on style, the high achievers were the lowest $(21 \%)$, and the low achievers were the highest (46.2\%) with the intermed iate achievers in between $(32.8 \%)$. With regard to the percentage of the re marks on the content in the total nu mber of annotations, on the other hand, the high achievers were the highest $(43.5 \%)$, follo wed by the intermediate achievers $(34.8 \%)$.

Although the high achievers had given close thought to the content and the organization before they started writing, when they were writing they continued paying attention to them. It can be concluded that when writing, the low achievers were engaged more in linguistic operations than the high achievers were. Therefore, with the improvement of their language proficiency they had fewer and fewer language problems, and so they could be engaged more in the content development of their composition.

Another difference between the subjects in different sub groups was in the way they made annotations. The annotations made by low achievers were general, and in fact the learners were try ing to pass the responsibility to the teacher, whereas the expressions made by high achievers showed that the subjects had thought about the problem before they made the annotations, and they could express their problems clearly. Compared with the high achievers, low achievers were less willing to think about their problems. When asked why they had made a few comments, most of the low achievers responded that it was useless to do so, since they believed that if they made comments, the teacher would only give suggestions, and then they had to revise their works. Therefore, instead of trying to use this technique in their writing, the low achievers regarded it as only a task, and they wanted to finish their task quickly rather than taking in seriously. Finally, another reason that might account for the lower number of annotations on the content and the organization of composition was that annotations on form were focused on discrete items, while content and organization concerned the macrostructure of the text those on form are related to microstructure of the text.

TABLE2.

DESCRIPTION OF EACH OF THE FIVECATEGORIES

\begin{tabular}{|l|l|}
\hline Content & familiarity with the subject matter, logic, cohesion \\
\hline Organization & coherence (sentence structure), appropriate format \\
\hline Standard English grammar, spelling, mechanics \\
\hline
\end{tabular}


TABLE3.

DESCRIPTION OF THE COMPONENTS OF EACH CATEGORY

\begin{tabular}{|l|l|}
\hline Grammar & $\begin{array}{l}\text { It tests adjectives and adverbs, conjunctions, and agreement bet ween subject and verb and between } \\
\text { pronouns and their antecedents. They look for common errors including compounding nouns, } \\
\text { missing subjects or verbs in a sentence, noun-verb agreement errors, split infinitives, plural - } \\
\text { singular verb mistakes, tense, and pronoun agreement. The subjects also edit for punct uation: They } \\
\text { check commas, colons, semi-colons, and full stops, as well. }\end{array}$ \\
\hline sentence structure & $\begin{array}{l}\text { It test relationships bet ween/among clauses, placement of modifiers. The subjects check the } \\
\text { clearness and precision at each sentence. }\end{array}$ \\
\hline mechanics & Use of apostrophes, hyphens, capitals, abbreviations and numbers \\
\hline cohesion & $\begin{array}{l}\text { The subjects check the link bet ween paragraphs. Do they have a topic for each paragraph? Do they } \\
\text { use connectives and references correctly? }\end{array}$ \\
\hline format & $\begin{array}{l}\text { The subjects check for typesetting: Are allthe paragraphs indented by the same amount? Is page } \\
\text { numbering sequential? Are headers and footers consistent? Does the layout have" Orphans" or } \\
\text { Widows, i.e. Do single words appear alone at the end or start of a page? Isthere any number page } \\
\text { left? Does the subject's name appear in the correct form? }\end{array}$ \\
\hline logic & $\begin{array}{l}\text { The subjects check the introduction of their writing. Does the introduction provide a map for the } \\
\text { body of writing? Does it have a "thesis"? Does the "thesis (main argument) comes through in the } \\
\text { writing? They also check the conclusion, does it summarize main points? }\end{array}$ \\
\hline
\end{tabular}

TABLE4.

COMMENTS MADE BY PARTICIPANTS IN EG

\begin{tabular}{|l|l|l|l|l|l|}
\hline \multicolumn{2}{|l|}{} & High achievers & Intermediate achievers & Low achievers & Total \\
\hline Number of students & 10 & 12 & 10 & 32 \\
\hline $\begin{array}{l}\text { Annotations on } \\
\text { content }\end{array}$ & Number & 100 & 80 & 50 & 230 \\
\cline { 2 - 6 } & $\begin{array}{l}\text { Percent in total } \\
\text { made by students }\end{array}$ & $43.5 \%$ & $34.8 \%$ & $21.7 \%$ & $100 \%$ \\
\hline $\begin{array}{l}\text { Annotations on } \\
\text { organizat ion }\end{array}$ & Number & 48 & 45 & 25 & 118 \\
\cline { 2 - 6 } & $\begin{array}{l}\text { Percent in total } \\
\text { made by students }\end{array}$ & $40.7 \%$ & $38.1 \%$ & $21.2 \%$ & $100 \%$ \\
\hline $\begin{array}{l}\text { Annotations on } \\
\text { spelling, grammar, } \\
\text { mechanics }\end{array}$ & Number & 128 & 200 & 282 & 610 \\
\cline { 2 - 7 } \\
\hline Tetal number of annotations & $21.0 \%$ & $32.8 \%$ & $46.2 \%$ & $100 \%$ \\
\hline
\end{tabular}

The results of all these studies demonstrated the effectiveness of portfolio assessment in instructional settings in that it encourages students to review their own work, gives them the opportunity to focus on their own points of strengths and weaknesses, helps them become active evaluators of their own needs, progress, achievement, and efforts, works as a instructional tool to help the subjects become independent learners, enhances the teacher/student relationships, enables the teachers to provide individualized instruction, gives the learners awareness of their own process of learning, engages them in critical thinking, makes them aware of learning strategies, facilitates students' learn ing process, and enhances their self-directed learning.

The result of this study is compatible with the result of some empirical studies. They include a learning portfolio study by Valeri et al. (2001), and a portfolio study performed by Marry (1990). The results of them indicated that selfassessment of writing and reading should be nurtured in progress. The learners can be trained to learn how to edit in order to promote learning, evaluate and change curriculu m.

\section{RESULTS AND DISCUSSIONS OF INTERVIEWS}

The subjects' responses to the questions put forward by interviewers were tabulated for each of them and the mean score for frequency of use was derived for each item. The questions include:

1. Did portfolio allow you to choose what you liked to write according to your personal interest?

2. Did portfolio help you understand your strengths and weaknesses?

3. Do you feel portfolio can present your learning results?

4. Did it take you a lot time to compile the portfolio?

5. Is compiling a portfolio a simple task?

6. Does portfolio provide a multi-dimensional perspective about learning?

7. Do you like to assess your own progress?

8. Do you like to be evaluated by pencil and paper tests?

9. Is portfolio a good tool to evaluate students' performance?

According to the learners' answers to the questions on the advantages and disadvantages of portfolio project the following results were achieved: most of the learners had positive reactions to the use of the portfolio. Forty-nine percent of the subjects strongly agreed that the portfolio writing allowed them to choose what they liked to write according to their personal interests. Also the portfolio assessment helped them understand their weaknesses and strengths. Seventy percent of the participants strongly agreed that the portfolio helped them realize their strong as well as weak points. Fifty-one percent of the answers indicated that the subjects had positive attitudes to the portfolio as 
presenting their learning results. They believed that the portfolio could show their results better than paper and pencil tests.

At the same time there were some disadvantages to the use of portfolio according to the learners' answers to the questions. Most of them believed that compiling a portfolio is time consuming (58\%) and sixty percent of subjects strongly agreed that compiling a portfolio was not a simple task.

When interviewed learners were asked to compare portfolios as an assessment means to traditional pen-and-paper tests, above fifty percent of them responded that they would prefer to be evaluated by portfolio, while only twenty percent preferred to be evaluated by paper-and-pencil tests. It may be due to the fact that portfolio offered them chances for self-evaluation because nearly sixty percent of subjects agreed that they liked to assess their own progress. Many agreed that the portfolio provided a multi-dimensional perspective to evaluation. The majority also agreed that multiple assessments should be used.

\section{LIMIT ATIONS}

These are some of the limitations of the study that might have affected the results include:

- One limitation of this study was the small sample size, which does not allow generalizations to other writers in other contexts

- Another limitation was the time period of the study. It was not long enough to show the real difference that selfcorrection and editing could make on writing.

- The third limitation can be the feedback the teacher provided. The teacher's feedback might not have been effective to some students.

- The fourth limitation of this study was the unfamiliarity of the subjects with portfolio development and portfolio assessment procedure. For some subjects we need more time to introduce portfolio.

- The fifth limitation of this study is the subjects' level of proficiency. The findings of this may only be valid for students at the advanced level.

\section{CONCLUSION}

With regard to the observed data the hypothesis was tested. The obtained results from Chi-Square test indicated that there was a significant difference among three sub-groups in experimental group. In other words portfolio assessment was helpful with learners' use of editing in their works. It is worth mentioning that they used this technique with difference focuses. High achievers were more concerned with macrostructure of language while low achievers focused ion microstructure of language or discrete items while editing. On the whole the tendency toward using portfolio assessment outweighed the traditional way of testing. Therefore, portfolio assessment improved subjects' writing proficiency, and enabled them to use editing successfully at the end of the study.

This study was an attempt to investigate the possible contributions of portfolio assessment to improving the strategy of editing in writing proficiency of advanced Iranian EFL learners along with their reactions and perceptions of portfolio and portfolio assessment. This work was carried out in a traditional-minded educational setting in which the dominant form of testing learners' writing ability was composing an assay overnight submitted at the end of the class. With regard to the observed data, the obtained results from Chi-Square test indicated that there was a significant difference among three sub-groups in experimental group. In other words portfolio assessment was helpful with learners' use of editing in their works. The subjects' responses to the questions were tabulated and the mean square for frequency of use was derived for each item. The results suggested that the students had positive attitudes to the use of portfolio. Majority of tem uttered their satisfaction in that portfolio assessment was a good tool to allow them reflect and evaluate their own learning. They believe that compiling a portfolio increased the learners' cooperative learn ing and mental growth in English. Different views were achieved on learners' understanding and perception of portfolio and portfolio assessment. A large proportion of the class thought of reflection as the most important part of portfolio assessment.

There were some advantages to using portfolio assessment. The subjects agreed that that portfolio allowed them to decide on what they liked to write. Portfolio assessment helped the subjects to come up with their strong and weak points, and provided the teacher with insights on adjusting pertinent feedback to the needs of students.

Although using portfolio as a form of alternative assessment to traditional testing was appreciated by majority of subjects, there were some drawbacks reported by them. Majority of learners believed that using portfolio assessment was a frustrating and time consuming task, and portfolio compiling was not a simple task. Due to the burden portfolio compiling put on students, it would not be a convenient way for students out of the classroom. On the whole the tendency toward using portfolio assessment outweighed the traditional way of testing. Therefore, portfolio assessment enabled them to use editing successfully and improved subjects' writing proficiency at the end of the study.

\section{IMPLICATIONS OF PORTFOLIO ASSESSMENT AND TEACHING WRITING PORTFOLIO IN EFL EDUCATIONAL SETTING}


Portfolio is increasingly integrated into EFL settings. We might use portfolio assessment in several ways to judge students' capabilities while they are engaged in learning English as a foreign language:

1. We might wish to show the progress in learning being made over a period of time by an individual student.

2. Samples of work can illuminate special features of learning which we may wish to highlight. They could show a particular strength in the student's work, or a particular difficulty which needs to be overcome. Presenting an example is often quicker and more meaningful than talking or writing about it, and a portfolio can be used as a substitute for or complementary to report about the students' learning.

3. A gathering of recent or current examples of the pupils work can ensure to show precisely the pupils current attainment and range of skills.

4. Where teachers are required to make high-stake judgments about individual pupils standards or levels, which may affect the pupils overall grade or his access to future opportunities, they may use examples of work to support and underpin an individual judgment.

A portfolio could also be used to illustrate the range and quality of the curriculum through examples of what the pupils have achieved within the activities planned and provided by the school. Individual teachers might use a portfolio produced by the pupils to illuminate the teacher's task design, her professional standards and expectations, and her capacity to motivate and stimulate her pupils. Such an assessment is important to describe the full range of a teacher's abilities over an extended period of time, and to stimulate reflection and improvement of a teacher performance. Portfolios are used by several groups, because in the list of purposes a particular audience is often implied. When we spell out the possible range of audiences we can see how a set of items might be of interest to a number of different audiences:

1. The audience might be the child himself or herself that that is interested in his own progress, strengths and aims for improvement.

2. Parents and care-givens too are important audiences, interested in the progress and development of their own children.

3. Teachers can use standard-based portfolios to share their understanding and expectations.

4. As the students move through the school and to the next teacher, a portfol io of purposefully selected items is available to use, so that teachers reach the right person at the right time.

5. In addition, the related audience can be next school to which the students are moving, providers and school governors that make decision about access to courses and jobs.

It is important to keep in mind that portfolio can be used for both assessment and instruction. The process of assembling a portfolio can help develop student self-reflection, critical thinking, responsibility for learning, and content area skills and knowledge. Portfolio enables teachers and students get a broader, more in-depth look at what students know and can do, and have a supplement or alternative to report standardized tests.

\section{SUGGESTIONS FOR FURT HER RESEARCH}

Research into this technique is new and still lacking. Studies with large number of subjects at various levels, and within a long time period are necessary to confirm the finding of this study. Future research should include some case studies to follow the writing process of the subjects, so that a clearer and more comprehensive picture can be revealed. Furthermore, so me other ways may need to be found for the training of the subjects, especially low achievers, on how to use editing in writing. Finally portfolio assessment and editing, like other innovations, must be undertaken with caution and thoughtfulness for it to fulfill its promise, and relegated to other skills.

\section{APPENDIX A. SAMPLE PORTFOLIO ASSE SSMENT FORM}

Student's Name: Date:

$\begin{array}{lllll}\text { Type of Assessment: Continuous } & \text { End of Project } & & \\ \text { Rating Scale: } 1 . \text { Excellent } & \text { 2.Very Good } & \text { 3.Good } & \text { 4.Fair } & \text { 5.Poor }\end{array}$

\begin{tabular}{|c|c|c|}
\hline Criteria & Rating & Comments \\
\hline \multicolumn{3}{|l|}{ Student selected appropriate material. } \\
\hline \multicolumn{3}{|l|}{$\begin{array}{l}\text { Portfolio showed evidence of student's understanding of } \\
\text { course objectives. }\end{array}$} \\
\hline \multicolumn{2}{|l|}{$\begin{array}{l}\text { Portfolio showed evidence of student's pride in own } \\
\text { work and commitment to writ ing project s/experiences. }\end{array}$} & \\
\hline \multicolumn{2}{|l|}{$\begin{array}{l}\text { Portfolio showed evidence that student completed } \\
\text { assignments. }\end{array}$} & \\
\hline $\begin{array}{l}\text { Portfolio showed evidence of student's understanding of } \\
\text { the process of developing and organizing portfolio. }\end{array}$ & & \\
\hline
\end{tabular}

Other comments: 


\section{REFERENCES}

[1] Allan, A.I.C.G. (1995). Begging the questionnaire: Instrument effect on reader's response to a self-report checklist. Language testing 12/2, 133-156

[2] Belanoff, P. \& Dickenson, M. (1991).Portfolios: Process and products. Portsmouth, NH: Boy nton/Cook Heinmann.

[3] Brown, H.D. (2001). Teaching by principles. An introduction to language pedagogy. San Francisco State University: Longman.

[4] Ferris, D.R. (1995). Students' reactions to teacher response in multiple-draft composition classroom. TESOL Quarterly, 29/1, 33-53.

[5] Hamp-Lyones, L. (1994).Interweaving assessment and instruction in college ESL writing classes. College ESL, 4/12 43-45.

[6] Marefat, F. (2004). Portfolio Revisited. IJAL, 7/2, 79-96.

[7] Marry, A. (1990). Talking about Portfolios. Quarterly of the National Writing Project and the Center for the Study of Writing and Literacy, 12/2, 1-3, 24-27.

[8] Moya, Sh.S, \& O’Malley, J. M. (1994). A portfolio assessment model for ESL. Educational issues of Language Minority Students, 13, 13-36.

[9] Mousavi, S. A. (2002). An Encyclopedic Dictionary of Language Testing. (3rd ed). Taipei: Tang Hua Book Company.

[10] Sutton, R. (1995). Assessment for Learning. Salford: R. S Publication.

[11] Valeri, G., Commandor \& Nannette, (2001).The Learning Portfolio: A valuable tool for increasing metacognetive awareness. Learning Assistance Review, 6/2, 5-18.

[12] Wiggins, G. (1989). Teaching to the (authentic) test. Educational Leadership, 46/7, 41-47.

[13] Yancey, B. (1996). Portfolio, electronic, and the link between. Computers and composition, 13, 129-133.

[14] Zamel, V. (1982). Writing: The process of discovering meaning .TESOL quarterly, 16, 195-209.

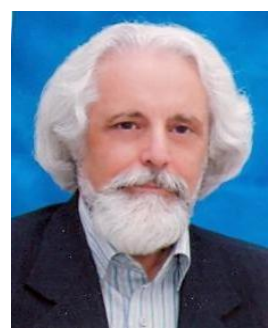

Mansoor Fahim was born in Nahavand in 1946. He received a Ph.D. in TEFL from Islamic Azad University in Tehran, Iran in 1993.

As for his professional background, he was a member of the faculty of English Language and Literature at Allameh Tabataba'i University in Tehran, Iran from 1981 to 2008 when he was retired as an associate professor of TEFL. He has taught English at a welter of universities. At present, he runs Research methods, Psycholinguistics, Applied Linguistics, Second Language Acquisition, and Seminar classes at M.A. level and First Language Acquisition, Psycholinguistics, and Discourse Analysis courses at Ph.D. level at a number of universities including Allameh Tabataba'i and Islamic Azad Universities. Moreover, he has several published articles and books mostly in the field of TEFL and has translated some books into Farsi.

Dr. Fahim is currently a member of the editorial board of some Iranian journals of Applied Lin guistic Studies.

Shahriar Jalili was born in Kermanshah, Iran in 1979. He received an MA in TEFL from khatam university in Tehran, Iran. He, with ten years of teaching experience, is a faculty member of English language at Azad university, Islam Abad branch. At pres ent he is teaching English in Azad university. His favorite field of research and study is testing and SLA. Moreover, He has two published books about general English. 